European Journal of Adapted Physical Activity, 1(1), 23-34

(C) European Federation of Adapted Physical Activity, 2008

\title{
DISABLED BODIES AND STORIED SELVES: AN EXAMPLE OF QUALITATIVE RESEARCH AND NARRATIVE INQUIRY
}

\author{
Brett Smith \\ Qualitative Research Unit, School of Sport \& Health Sciences, University of Exeter, UK
}

Based on life history data, this qualitative article explores the self-perceptions of a small group of men who, due to a spinal cord injury (SCI) through playing rugby union football, have made a transition from the world of the able-bodied into the world of disability where they remain to this day. The most common kinds of perceptions of self used by the men through telling their stories as they live post-SCI is focused upon in detail. The narrative analyses reveal that three types of narratives help structure and shape the ways in which these men storied their embodied perceptions of self. For the majority of the participants, the restitution narrative was drawn on, and this helped structure a restored self and entrenched self, and was linked to a disciplined body. In contrast, two people told quest narratives that constitute a perception of a self that is developing and affirmative, and a body that is communicative. For one person, the chaos narrative was foregrounded that resulted in a fragmented self-perception and a chaotic body in action. The implications of all this for disabled people's body-self relationships are critically considered.

KEYWORDS: Disability, Narrative, Self, Body, Sport.

\section{INTRODUCTION}

Imagine having a life story that in-thetelling involves being a fit, able-bodied, young man with a highly muscular and controllable body who loves playing sport and rugby union football in particular. Also imagine a life story in which, over the years, the central themes have revolved around the development a strong athletic identity and a sense of self based on a performing body. Now imagine this.

I'm running with the ball, ten metres from scoring a try and from out of nowhere someone hits me from the side. I hear this massive crack, as if someone had fired a gun, and I fall to the floor, my face flat in the mud. One moment I'm playing rugby, enjoying the game, and then from the tackle, bang! I break my neck. I go from able-bodied to disabled in a split second... My life is thrown apart.

This is the moment, immortalised in time, when Jacob, a single man, highly dedicated rugby player, and lorry driver, suffered a spinal cord injury (SCI) at the $\mathrm{C} 5 / 6$ level that propelled him across the border from the world of the able-bodied into the world of disability where he remains to this day. Suffering a SCI while engaged in the aggressive contact sport of rugby union football is a major epiphany and a biographical disruption. As such, it instigates a multiplicity of difficult and complex issues a person has to deal with. One important issue revolves around self-perception.

Within the field of sport and exercise in general and adapted physical activity in particular, research on disability and people's self-perceptions has been dominated by quantitative approaches to understanding. When done well, these have been, and are often, important and useful. However, there is an alternative approach to inquiry. Qualitative research, in the hands of a small group of researchers, has emerged in recent years as something different from quantitative research that is valuable in and of itself as a way of developing and enriching our understandings. It is a vocation that is ripe with possibilities. With this in mind, this article draws upon life history data from an ongoing qualitative study to explore the narratives and perceptions of self as of a small group of men who have suffered SCI while engaged in rugby union football. Before turning to these, however, it is useful to first offer a theoretical prologue to 
how I, as a qualitative researcher who has a proclivity for narrative theory (Smith, in-press; Smith \& Sparkes, 2006), conceptualise self.

\section{Theoretical prologue: Storied selves}

In recent years, as part of the 'narrative turn' in the social sciences, a growing number of scholars have argued that we live in a storyshaped world (Bruner, 2002; Frank, 1995; Smith \& Sparkes, 2006). An important insight coming out of this ontological position and wide-ranging literature is that our selves and identities are constituted through narratives. That is, researchers ascribe a particular ontological character to people, as storied selves, and this notion provides the basis for understanding people's lives and how they perceive themselves. For example, Gergen (1994) argues that our self-perceptions are not to be found simply inside a person or in cognition, but rather are constituted through narratives in relation to others.

Persons... do not consult an internal script, cognitive structure, or apperceptive mass for information or guidance; they do not interpret or "read the world" through narrative lenses; they do not author their lives. Rather, the selfnarrative is a linguistic implement embedded within conventional sequences of action and employed in relationships in such a way as to sustain, enhance, or impede various forms of action (p. 188).

Furthermore, according to Dennett (1991), the brain mechanisms underlying consciousness are both distinct and incomplete. Brain processes operate independently without the benefit of a hierarchical structure that puts information together to form a complete picture. What we know about the world and ourselves is actually much more piecemeal, choppy, and full of holes than we recognise. This presents us with a fascinating, and underappreciated, problem: How do we create a sense or perception of ourselves as whole and consistent when what we truly know is so fragmented and disorderly? To go one step further, how do we create a perception of self or identity with the inadequate resources that we have to work with? Dennett responds that filling in the gaps and providing us with a sense of consistency is a centre of narrative gravity. There is no real or true self that exists as some entity in our brain. Rather, the stories that we compose, in the social medium of language, function to create to the illusion of seamlessness in our self-perceptions and a sense of self-sameness. Similarly, Riessman (2003) argues that narratives provide a structure for our self-perceptions and very sense of selfhood. Thus, "We 'become' the stories through we tell our lives... Telling stories configures the "self-that-I-might-be" " (p. 7).

Accordingly, while the individual story and their perceptions of their selves and others may seem unique to the teller, they are, in fact drawn from a cultural repertoire 'out there' in society and are a social creation. As Frank (1995) argues, the disabled or ill body's articulation in stories is a personal task, but the stories told by the disabled or ill are also social. People tell their own stories, but people do not make up, by themselves, how to tell these stories. We each speak our own thoughts, but we speak in a syntax and vocabulary that language provides, and we do not make this language up ourselves. Just as our selfexpression is constrained by syntax and vocabulary, so our storytelling ability is constrained by what narrative types, maps, or what some call templates, a society makes available for us. Any culture, at any given time, has a certain number of these narrative types. To be able to tell a story - to get the story told and make it intelligible to others - a speaker has to use one of these available narrative types, maps, or templates.

In a similar fashion, McAdams (2006) proposes that, although people tell their own unique stories of disability, they compose these stories by adopting and combining narrative types that culture makes available to them.

Culture provides people with a menu of narrative forms and contents from which the person selectively draws in an effort to line up lived experience with the kinds of stories available to organize and express it. Indeed, the story menu goes so far as to shape lived experience itself: we live in and through stories. Stories are made and remade, 
performed and edited, instantiated, contoured, and lived out in the social ecology of everyday life and with respect to the norms of narrative content, structure, and expression that prevail in a given culture (p. 16).

Therefore, from a qualitative perspective in general and narrative in particular, an individuals' self-perception is shaped by the narratives they draw on and appropriate from the wider culture and society in which they are immersed. Whilst not determining, people use narratives to make sense of their lives, to give their lives meaning, and make each selfperception intelligible to not only themselves, but also others. Seen in this light, narratives do matter. They are important resources to explore people's self-perspectives of disability, sport, and physical activity.

\section{METHODS}

This article focuses upon the life stories of fourteen, white, predominantly working-class men, aged between 26 and 51. Their years of age when they sustained a SCI ranged from 16 to 35. Having gained ethical approval from the University of Exeter Ethics Committee, initial contact was made with the participants via an open letter in a newsletter circulated by the English Rugby Football Union's support network for injured players. The participants then contacted the investigator prior to engaging in a series of confidential, taperecorded, life history interviews. Each participant was interviewed three times over a period of a year, with each interview lasting from two to five hours. The total time spent interviewing was two hundred and twelve hours.

All interviews were tape-recorded, transcribed, and subjected to a categoricalcontent analysis and a holistic-form analysis (see Lieblich, Tuval-Mashiach, \& Zilber, 1998; Smith \& Sparkes, 2008a). The holistic-form analysis focuses on the formal plot and organisation of the narrative to tease out the distinct structures that hold it together with a view to identifying it as a particular narrative type. With regard to a content mode of analysis, rather than examining the structure of stories as a whole, the researcher seeks central themes, typologies or instances of paradigmatic categories within the narratives told. Here researchers look for similarities in the data and then create categories to organise the data as a collection of specific instances. This process also seeks to identify relationships among categories.

In combination, the analyses revealed that three types of narratives structured and shaped the ways in which this group of men storied their perceptions of self. That is, for the majority of the participants, the restitution narrative helped structure a restored self and entrenched self. In contrast, for two men, the quest narrative constitutes a perception of a self that is developing and affirmative. For one person, the chaos narrative resulted in a fragmented self-perception. Importantly, all these were associated with specific kinds of body. Each of these narratives and their associated body-selves will now be focused on in turn.

\section{Recapturing the past self: The restitution narrative and restored and entrenched selves}

The restitution narrative, as one dominant narrative type or template available within society, was drawn on by, and framed, eleven of the men's personal life stories. According to Frank (1995), the plot of this narrative has the basic storyline: 'Yesterday I was healthy, today I'm sick, but tomorrow I'll be healthy again' (p. 77). For these men, this translates to, 'Yesterday I was able-bodied, today I'm disabled, but tomorrow I'll be able-bodied again.' For the men who told restitution narratives, there was the perception that they will at some point in the future recapture their past selves. Here, they aim to reclaim the same identities, the same lives that they before SCI. Nothing less will do. For these men, their 'real' selves are and must be only the former and past self. The halcyon days of playing able-bodied sport, working again, and being physically active are perceived as obtainable and integral to regaining a positive and healthy perception of one self. Thus, in the face of SCI, these men 
reject disabled sport and opt for what Charmaz (1987) called a restored self.

The restored self, translated to disability and sport, is an identity level in which people expect to return to their former lives following SCI. This is viewed as a 'normal' or 'natural' response. The men who desire this identity level thus aim both to reconstruct a similar physical self as before and assume continuity with the self they had before they became disabled. The desire for a restored self, along with an affinity for a restitution narrative, is reflected in the following comments made by Harry:

I want to walk again in the future, and I believe I will. I don't like this body, and I want to repair it as soon as possible. Whether that will be in the next ten years, I'm not sure, but that's where I see myself... I see myself walking again, and that's a good thing because it will mean I'll get my old life back, and who I really am, so that can only be good... I'll fight until the day I die, I won't give up, and from what I read, and hear from television, then I don't think I'll be let down. You see, medicine will find a cure and I will get back my old self... And disability is definitely a tragedy. I can't say anything positive about disability. I want to get back my old life.

Similarly, framed by the demands of the restitution narrative, Paul and Eamonn view disability through the tragedy narrative of disability, and in response develop a selfperception revolving around attempting to reclaim the same lives that they had before they became disabled through playing sport. For Paul:

I want a cure. I don't want to live like this any minute longer than I have to... I want my old self back, the real me, and I see medicine playing a huge part in that... As well, since I see a cure as helping me overcome my problems, and the body's mess, then that's want I want... The cure will be some sort of regeneration, or maybe implants the latest newsletter tells me, but whatever it is, as long as I can get back as much functioning as possible, to be able to repair my body some how, then that's all that matters... At the end of the day, disability is a tragedy, I can't see how you could look at it any other way, and because of that, I think that medicine is doing a great job trying to find a cure. So at some point I'll make a comeback.

Similarly, according to Eamonn:

When I think about my past I know I want it back again... I want my old self back. And to be honest I do think that I will get my past back, y'know and be my old self again. I say this because the knowledge we now have changes with each day... Medical advancements are more and more frequent and I don't think it will be far into the future when a cure for spinal injury is found... And when that day comes, y'know, when I can walk again, then I will get myself back... and the old times will come back... I just have to wait and keep my hopes up. I'll get my old body back. My perception of myself is my old body.

It would seem, therefore, that for the men who told restitution stories a desire to return to prior body-self relationships is important for them. In this sense, within the types of restored selves identified by Charmaz (1987) they hold onto an entrenched self. Restoring an entrenched self means being wedded to a clear self-conception situated in the past. This self represents patterns of action, conviction, and habit built up over the years. These unchanged patterns had been a source of self-respect before they experienced SCI and became disabled, and once science has 'repaired' their broken bodies, resuming these patterns becomes the person's major objective. Hence, restoring an entrenched self conjures up the perception of a 'comeback' which is a popular and powerful narrative in sporting cultures.

Importantly, rather than existing in an incorporeal world and simply being about SCI, this relationship between the restitution narrative and the restored and entrenched self is told through, in, and out of a biological, lived, and social body. This body can be termed a disciplined body. According to Frank (1995), the disciplined body is deeply concerned with action problems about control, and this body experiences it's most serious crisis in loss of control. Thus, after SCI the person cannot accept the contingency of the body and instead wants the body's former predictability back 
again. This is particularly so given the emotional feelings of embarrassment, boredom, helplessness, and frustration that partly results from the body's loss of control within a society that values and demands controllable bodies.

Further, with a loss of spontaneity, emotional control, and an independent life, wanting to regain control and reassert predictability through a future technologicalmedical cure is strengthened (Smith \& Sparkes, 2005). Moreover, the disciplined body is fundamentally monadic in its relation to other bodies. Indeed, it does not relate to other bodies, but rather pushes them away. That is, the disciplined body may be among others, but is not with them. It also speaks of "having" a SCI and this talk about "having" turns the monadic body in upon itself. Hence, according to Frank (1995), the body "that turns in upon itself is split from the self that looks forward to this body's restitution. The temporarily brokendown body becomes 'it' to be cured. Thus the self is dissociated from the body" (p. 85). As well as in the comments above, all this can be seen in the following comments by Jacob:

I used to have such a strong, powerful sporting body, and now, I sit here in a wheelchair. I hate it. I hate being disabled. I want to walk again. And I will. That's my hope. And a cure will come. Stem cell surgery will arrive and then I'll be able to walk again, get my old self back, and not have to deal with this body. You see, whereas before the body was no problem, now its one constant problem. It won't move. I will, in the mind, I will the legs to move, but they won't. That's frustrating. I can't shower myself properly. I can't control my bowels either. That's damn frustrating too, and sometimes embarrassing. Having an accident, you know, losing control of your bowels when I'm out is awful. I feel helpless to do anything, and yet there it is, the smell... Living in it, this body, means that I've lost all spontaneity. Everything needs planning. Going into town at a whim, it's just too much effort. So I don't do much. I just sit here and wait for a cure... I don't need anyone, or feel close to anyone now. In fact, I've probably pushed most people away. I'm not the happiest of people to be around. And I blow up over the smallest of things. I don't even have control over my emotions. Having no control over it [the body], that's what it boils down to. Living like this is not what I want. Getting back my old body, my old life, is what I want. I will walk again.

\section{The radical new self: The quest narrative} and developing and affirmative selves

In terms of experiencing SCI via sport, quest stories meet suffering head on; they accept impairment and disability and seek to use them. As Frank (1995) notes, just what is quested for may never be wholly clear, but the quest is defined by the person's belief that something is to be gained from the experience. Two of the men here (David and Doug) told this type of story about themselves during the interviews. Further, in contrast to the restitution narrative that incorporates perceptions of restored and entrenched selves, quest stories as different narrative types or templates foster a radical new self-perception that can be described as developing self.

Drawing on the work of Charmaz (1987), the developing self can be seen in action with the men in this study when the direction of their lives concerns them as well as the character of the self they shape, rather than commitment to specific prior activities and prior identities. Instead, these men commit themselves to growing and developing in the future. When narrating a developing self, the men emphasise reconstructing their ability to shift and change as well as to explore new identities as possibilities emerge. This selfperception is suggested in the following exemplar:

Brett: In the last interview you said that you felt a sense of being reborn and...

Doug: Yes, sure. Well, I suppose as I say it is like a drastic change, what happened with breaking my neck and becoming paralysed from the chest down. Because the attitude I like to take is yes, we all suffer things that are bad, not bad but negative and they can be life changing. It's what you do with that. If you can turn it round so that it can benefit you and also so that it can benefit others, you know, that's great. You need to learn from these things... I 
think then, yes, I have been reborn, become a much better person because of everything. People assume it's all bad, yeah there are bad days, some real shitty ones, but life for me is generally good. Real good... I've grown as a person... Hearing people's stories who have also changed for the better, and knowing that it was possible to be a different person, also helped me to become this different person... I've accepted disability, which means changing... [It means] knowing that I don't have to struggle against my body... Instead I can now say that I can't control my body which again is acceptance... Because of this, I've now come to the point today where I can say that I don't want to go back to being able bodied, that I'm more than happy with my current situation. And that's acceptance now as well... I'm happy being disabled, it's not a tragedy, and I really wouldn't go back.

Not only did David and Doug as tellers of quest narratives suggest a perception of self as developing, but also one as affirmative. Drawing on the work of Swain and French (2000), and the idea of the social model (Shakespeare, 2006), the affirmative self is a non-tragic perception of disability and impairment that encompasses positive selfperceptions, both individual and collective, for disabled people grounded in the benefits and life experiences of being disabled. For example, Doug commented, "As a person, I've grown, and become aware that being disabled is communal issue, and we should be proud not depressed about being disabled. I'm happy and proud of my body and who I'm becoming." Likewise, for David:

After breaking my neck I needed another way of looking at life if I was to really make a huge change and difference to my life... Through a friend I met at university who took politics, I began looking for ways to see disability in a more positive light, and that came through seeing disability not as a medical issue, but as a social one... And knowing its not simply an individual issue or a tragedy, but also its about helping people, being a group, and realising that disability can be a positive experience. And knowing that other people are in the same boat as you is very useful... knowing that helped me realise that I'm not alone... It's about saying that it's okay to be different. In fact it's more. It's about saying that we have rights, and society needs to start changing, if that change needs to take place at the local level, as well as at government level, then perhaps that's what I can offer... I don't go on the disabled rights marches that you see on the news, but that's because I see myself working at changing things at a local level. Y'know, teaching the children about different ways of living... challenging norms with friends, and even talking to strangers I think offers something. It may not be anything profound, but if what I say can make people think twice about disability and how we live, then that's good enough... I've got a very positive perception of myself as a disabled person, and I'm happy being disabled, and I can now sometimes help others.

As these comments suggest, perceiving the self as affirmative and developing may be liberating for some people and help in the process of reconstructing selves and identities by providing a sense of communal consciousness and expanding the cultural repertoire of stories on which to draw when replotting a life (Smith \& Sparkes, 2004, 2005; Sparkes \& Smith, 2003, 2005). It can also enable the reconstruction of selves following SCI through sport by resisting and deviating from standard plots and dominant medicalised assumptions about disabled people (e.g., disability is a tragedy that results in life being perceived as effectively over). In so doing, it displaces the tragedy storyline and medical model that can restrict opportunities to tell new stories and engage with a range of future possible identities that are a necessary part of self-perceptions as developing and affirmative self. Thus, the developing affirmative self can have liberatory, therapeutic, and transformative possibilities for some individuals and communities by legitimising different ways of living as a disabled person and making available alternatives self-perceptions to the dominant ones within the cultural of disability so that people can have a diversity of resources to draw on if they so wish and as the needs of their circumstances emerge. 
Importantly, as tellers of quest narratives who narrate self-perceptions as developing and affirmative, David and Doug also reveal the emergence of a communicative body. As Frank (1995) notes, this kind of body is associated rather than dissociated with itself. It also accepts the body's contingency. Thus, unlike the disciplined body, this body recognises and challenges the myth of control that prevails in Western cultures in relation to the body, and being able to change it from a disabled one to an able-bodied one. Importantly, this does not lead the participants to depression or emotional distress, but instead releases them from the shackles of trying to regain control and predictability, thereby opening up more opportunities to enjoy life as a disabled person. It means that contingency and disability is now accepted as part of the fundamental contingency of life that is influenced by numerous factors, many of which are beyond the control of the individual. Further, instead of being monadic in its other-relatedness, signs of a communicative body seeking to exist in a dyadic relation to others are evident in the quest stories told above, and in the one below by David:

Disability for some people is the worst thing that could happen to them. But for me, no. It's one of the best things that have happened to me. I'm happy, and I'm doing something with my life as a proud disabled person. I'm not preaching here. I just think I can teach people that it's okay to be disabled, and it's not the end of the world, quite the opposite in fact. It can be great, and I've learnt so much, met so many great people, and have totally changed for the better because of it all... I've become a new person. I'm happy with my body. I'm in a wheelchair, I can't feel my legs, and I can't control much of my body. But that's okay. I accept that my body can't do some things. That's not a problem because that's part of being disabled. Which I wouldn't change. I've just got a different body. So what that I sometimes fart, but lose control of my bowels, y'know, sometimes have an accident in public. So what if I'm not ready to do things at a drop of a hat. None of that matters or gets me down. Becoming disabled wasn't the end. It's a new start. And I wouldn't go back.

Therefore, within quest narratives told following becoming disabled through sport, SCI and disability is storied as an opportunity, albeit difficult one, to generate radically new selves. Indeed, for David and Doug, their selfperception was one of developing and being affirmative. All this, moreover, was embodied.

\section{Narrative wreckage: The chaos narrative and fragmented selves}

In contrast to the restitution narrative that attempts to outdistance mortality by rendering disability transitory, and the quest narrative that meets disability head on, is the chaos narrative. According to Frank (1995), this narrative imagines life never getting better. It can result in despair, the loss of any kind of hope, and a feeling of being overpowered by all experience that, like a psychological black hole, all possible perceptions of self development are absorbed. In the face of this, narrative wreckage ensues and selves become fragmented. Jamie, a forty-four year old former crane driver, who acquired a SCI at the age of thirty-five, was the only person in the sample whose life was, and remains, in chaos following SCI. For him:

I used to be happy. Life was good. Now it's over... My life ended when I broke my neck playing rugby. I cannot walk, play rugby, breathe on my own, or see my children when I want. Life is over. It's not worth living now... I feel nothing. Feel, it's shattering, shattering. The whole thing, just completely shattering. Life has been, it's been beaten, life's been beaten out of me... My life is a mess now. I can't remember when I was happy last. I feel, I feel, dead now. Since the accident, it's like this all the time... Then, then, I, I don't know. My life is over. It is over. Over. I've gone... I may as well be dead. The accident has left me with nothing. No one... Life has, has, stopped. I have no life left in me now. Just darkness. Darkness. I'm worthless. And then, then, life has ended. It's an empty existence... Being disabled, people don't want you. I can't blame them. I can't get into most buildings. I can't see people employing me when I need lots of space and good access. I'd like to see my 
children more. I can't visit them though... There are too many obstacles. No transport... The pave-ments are not made for what has happened to me. I can't move in the same places as my children... I'm alone now. Life is over for me... I am alone in this world. Then, then, life won't improve. Nothing to live for. It can only get worse. I may as well be dead.

As these comments suggest, initiated by the actual SCI itself, and maintained and accentuated by a deprivation of opportunities (e.g. socio-structural issues), Jamie has moved into chaos (Smith \& Sparkes, in press b). In this movement, his psycho-emotional wellbeing is battered. His world is unmade, reduced to nothing, and narrative wreckage follows. Thus, not surprisingly, his percept-ions of self are fragmented as their narrative structures break apart to the point where life is deemed to be meaningless and devoid of purpose and hope (Smith \& Sparkes, 2005).

Jamie's movement into chaos in relation to SCI is also associated with the emergence of a different kind of body. This is a chaotic body. According to Frank (1995), this kind of body defines itself as being swept along, without control, by life's fundamental contingency. Indeed, efforts have been made to reassert the predictability of the former body-self but these efforts have failed, and each failure has had its costs. Therefore, while contingency is not exactly accepted, it is taken as inevitable. In other words, any belief that disability is curable or the body is controllable is none existent since, on a timeline, it is perceived this is how the situation is now, and forever (Sparkes \& Smith, 2003). This, in turn, helps feed and sustain adverse emotions reactions, such as sadness, and the perception that the situation and ones emotional well-being will not change or improve over time.

Moreover, contributing to all this, the body is so degraded by the overdetermination of SCI that survival often depends on the self's dissociation from the body. At the same time, the body as 'it' becomes monadic in terms of relating to other bodies. Here, the individual body is closed in upon itself and isolated. As a result, there is a lack of social support (e.g. emotional) available and a wall is erected around the teller that makes receiving support problematic. The (dis)embodiment of chaos is echoed in the following comments (see also Smith \& Sparkes, 2008b):

The day I broke my neck is the day my life ended. It's over. No hope. Nothing. It, this body, is nothing now. Nothing I can do about it. I am no one now. I may as well be dead. No one in my life. Everyone has left. I, then, then, what do I have? Nothing. I don't need anyone's support now. It's over. The body survives. Nothing I can do with it or about it. Life has ended... I am alone, and it [the body] survives, but it's not an existence. I live in darkness, in a body that has no life. Life is over.

\section{Closing thoughts}

In this article, an attempt has been made to illuminate the most common kind of selfperceptions used by fourteen men who have become disabled through sport. Despite the majority of the men drawing upon perceptions of self to help them understand and impose order on their experiences, important differences were identified in the kinds of self perceived and the influences of these in reconstructing body-self relationships. It has been suggested that the differences are due, in part, to the power of the restitution, quest, and chaos narratives to shape experience in general, and the kinds of self-perceptions used in personal accounts, in particular. Thus, selfperceptions are, at least in part, storied. They are accessed, developed, and experienced through the narrative templates or types one has available to draw on.

For the majority of the men in this study, their experiences were shaped by the restitution narrative that led them to articulate a restored and entrenched self. The usefulness of this narrative and its affinity to these selfperceptions should not be underestimated. Indeed, I have no wish to denigrate them or underestimate their value in certain sets of circumstance. Yet, there are a number of limitations and dilemmas that go with restitution narratives and restored and entrenched perceptions of self that need to be acknowledged if we are to develop a critical impulse. For example, one limitation of the 
restitution narrative noted by Frank (1995) "is the obvious but often neglected limitation of the modernist deconstruction of mortality: when it doesn't work any longer, there is no other story to fall back on. Restitution stories no longer work when the person is dying or when impairment will remain chronic" (p. 94). Thus, problems may arise when the disabled person does not find restitution, when the body is not fixed or cured.

Another limitation highlighted by Frank (1995) is that restitution is increasingly a commodity that some can purchase and others cannot. Here we might imagine the individual finding that a 'cure' for SCI has been found but is unable to afford this cure. As Frank notes, "High-tech medicine offers more and more restitutions that fewer and fewer people will be able to afford" (p. 95). Therefore, the restitution story as a generalized narrative of disability is likely to become increasingly restricted in its availability. Further problems arise when people become fixated on one kind of body and sense of self in circumstances where the restitution narrative is not appropriate (Sparkes, 1998). Moreover, according to Shakespeare (2006), a "practical problem with the cure agenda is the way that new medical research findings are associated with hyperbole and raised expectations, which do not then translate into benefits" (p. 110).

Furthermore, like Charmaz (1994) suggests, people can lapse into despondency and a tragedy view of disability when they cannot recapture their self-perceptions of who they were prior to SCI. Likewise, the restitution narrative, and restored and entrenched selves, may be limited and problematic since being unable to measure up to the self-perceptions based on the past bodyself can result in further preoccupation with them, and can heighten identity dilemmas. As the distance increases between a person's past body-selves (now reconstructed in memory in idealised form) and present identities, the former valued identities collapse and new ones are viewed as negative. Significantly, with each identity loss due to SCI the preservation of valued, past, performing identities becomes increasingly difficult. Indeed, idealised accounts of, and a preoccupation with, the past can serve as a painful index of what had been lost, and what now has to be 'endured' on a daily basis. In this context, feelings of frustration, anger, and depression are common.

In contrast to ways in which the majority of the men's embodied self-perceptions are shaped by the restitution narrative is the quest story told by David and Doug. In this narrative, SCI is reconfigured as a challenge and an opening to other ways of being as part of a developing and affirmative self, and a more communicative body that acts for others, and connects in a dyadic fashion with them, emerges. In this situation, with its emphasis on being socially connected rather than selfsufficient and monadic, there is the opportunity to engage in acts of generosity toward others and toward oneself, and situate SCI within a project of eudaimonia or human flourishing. As Frank (2005) argues:

The project of human flourishing depends on a recognition that no matter how professional or expert anyone thinks she or he is, no matter how personally authentic anyone wants to be or wants to allow others to be, none of us is ever self-sufficient: two is the minimum number. What we all have within ourselves is a potential for dialogue. Care is generous when it allows people to flourish ( $\mathrm{p}$. 294).

Furthermore, communicative bodies that tell quest stories and developing and affirmative self-perceptions can provide a political challenge to presumptions that disability is always a tragedy and act as a point of resistance against the dominant master narratives revolving around notions of a medical cure that are so persuasive and powerful in Western cultures. Equally, by telling and sharing stories, they potentially can generate communal and collective stories of disability that instigate social as well as individual change in the face of oppressive structures. Thus, in combination the quest narrative and developing and affirmative selves might have a revelatory, liberatory, and transformative impact on disabled people by making available and legitimising different ways of living as a disabled person. For 
instance, it can suggest it is social barriers which help create and sustain disability, thereby inviting people to feel that they and their impaired body aren't at fault: society is, and it is society which needs to change. Thus, this response may engender self-confidence and pride, rather than guilty knowledge and shame.

It needs to be acknowledged, however, that there are potential problems with the quest narrative and associated developing and affirmative self-perceptions. For example, Frank (1995) points out that the "risk of quest stories is like the risk of the Phoenix metaphor: they can present the burning process as too clean and the transformation as too complete, and they can implicitly deprecate those who fail to rise out of their own ashes" (p. 135). Some might also see affirmative and developing self-perceptions as being too reliant on political rhetoric, and dismissive of those who covet a cure, thereby negating diversity and difference (Shakespeare, 2006). Notwithstanding such issues, it would seem that, the embodied quest narrative and developing and affirmative self-perceptions have empowered David and Doug to alter the trajectories of their lives and infuse their history with new meaning and complexity. It is also helpful in terms of enhancing his ability to explore different body-self relationships and experience life differently as a disabled man.

Set against the restitution and quest narratives is the chaos narrative that shaped the experiences of one of the men in this study. For Jamie, the rising tide of the experience of SCI rolls relentlessly over him. In this scenario, narrative wreckage, the embodiment of chaos, and a fragmented self-perception ensue. All of which can contribute to what Freeman (2003) terms narrative identity foreclosure. This involves the premature conviction that one's life story is effectively over. In such instances, Freeman suggests, if one already knows, or believes one knows what lies ahead, then one may become convinced that there is little value in lasting to the very end. Consequently, one's life may seem a foregone conclusion and, therefore, devoid of hope and future valued self-perceptions.
Clearly, living in chaos is no way to live. In view of this, and because this story is difficult to listen to, it is often tempting to try to fix chaos. Yet, as Frank (1995) suggests, such a response imposes the restitution narrative and denies the persons experiences and chaotic self-perceptions. For him, then, it is important not to try to fix chaos, although that will be the first reaction of most health professionals. Indeed, some people's lives are deeply chaotic and will not be fixed, at least quickly. The person living the chaos story will see others' attempts at fixing not as help but as their own self-protection against what others' (e.g. health professionals) find frightening. Thus, for Frank, one of the worst things people can do to someone in the chaos story is rush or push them to move on.

Moving on is desirable; chaos is the pit of narrative wreckage. But attempting to push the person out of this wreckage only denies what is being experienced and compounds the chaos. The anxiety that the chaos story provokes in others leads to the standard clinical dismissal of chaos stories as documenting "depression". When chaos is thus defined as a treatable condition, the restitution narrative is restored. Clinical staff can once again be conformably in control: the chaos can be dismissed as the patient's personal malfunction. That reality is classified as either amenable or resistant to treatment: in either case, it no longer represents an existential threat (p. 110).

Therefore, what might be needed to help a person move out of chaos is an enhanced tolerance for this narrative as a part of a person's life story by all those connected to them. As Frank (1995) emphasises, if the chaos story is not honoured, the world in all its possibilities is denied. For him, to deny a chaos story is to deny the person telling this story which means that they cannot be cared for. It also sentences them to narrative silence. As Frank points out, "people can only be helped out when those who care are willing to become witnesses to the story. Chaos is never transcended but must be accepted before new lives can be built and new stories told" (p. 110). Accordingly, whilst certainly not easy (see Smith \& Sparkes, in-press), a person 
might well need stay with the chaos, listen with it, and not be destroyed by it.

In the spirit of enriching the possibilities of research and inviting dialogue across methodological boundaries I hope this article, as an example of qualitative research from a narrative perspective, will encourage researchers in adapted physical activity to reflexively consider utilising this way of understanding in the future. Certainly, doing narrative research in a reflexive, informed, and responsible manner is no easy task. However, it is not impossible. For me, the effort and risks involved are worth taking because narratively framed qualitative research provides a powerful means of understanding disability in new and exciting ways. As such, I feel it is a worthy addition to the methodological repertoire of researchers as they explore the complex domains of adapted physical activity.

\section{ACKNOWLEDGMENTS}

I would like to thank José Pedro Leitão Ferreira for his interest in my work and care of the self as a scholar. A special thanks to the fourteen men for their acts of generosity in sharing their stories with me.

\section{REFERENCES}

Bruner, J. (2002). Making stories. Cambridge, MA: Harvard University Press.

Charmaz, K. (1987). Struggling for a self: Identity levels of the chronically ill. In J. Roth \& P. Conrad (Eds.), Research in the sociology of health care, Vol. 6 (pp. 283321). Greenwich, Connecticut: JAI Press Inc.

Charmaz, K. (1994). Identity dilemmas of chronically ill men. The Sociological Quarterly, 35(2), 269-288.

Dennett, D. (1991). Consciousness explained. Boston: Little and Brown.

Frank, A. (1995). The wounded storyteller. Chicago: The University of Chicago Press.

Frank, A. (2005). Generosity, care, and a narrative interest in pain. In D. Carr, J. Loeser, \& D. Morris (Eds.), Narrative, pain, and suffering, Vol. 34, (pp. 289-300). Seattle: IASP Press.
Freeman, M. (2003). When the story's over: Narrative foreclosure and the possibility of self-renewal. In M. Andrews, S. Day Sclater, C. Squire \& A. Treader (Eds.), Lines of Narrative (pp. 81-91). London. Routledge.

Gergen, K. (1994). Realities and relationships: Sounding in social construction. Cambridge, MA: Harvard University Press.

Lieblich, A., Tuval-Mashiach, R., \& Zilber, T. (1998). Narrative research. London: Sage.

McAdams, D. (2006). The role of narrative in personal psychology today. Narrative Inquiry, 16(2), 11-18.

Riessman, C. (2003). Performing identities in illness narrative: Masculinity and multiple sclerosis. Qualitative Research, 3(1), 5-33.

Shakespeare, T. (2006). Disability rights and wrongs. London: Routledge.

Smith, B. (in-press). The state of the art in narrative inquiry: Some reflections. Narrative Inquiry.

Smith, B., \& Sparkes, A. C. (2004). Men, sport, and spinal cord injury: An analysis of metaphors and narrative types. Disability \& Society, 19(6), 509-612.

Smith, B., \& Sparkes, A. C. (2005). Men, sport, spinal cord injury, and narratives of hope. Social Science and Medicine, 61(5), 1095-1105.

Smith, B., \& Sparkes, A. C. (2006). Narrative inquiry in psychology: Exploring the tensions within. Qualitative Research in Psychology, 3, 169-192.

Smith, B., \& Sparkes, A. C. (2008a). Narrative and its potential contribution to disability studies. Disability \& Society.

Smith, B., \& Sparkes, A. C. (2008b). Changing bodies, changing narratives and the consequences of tellability: A case study of becoming disabled through sport. Sociology of Health and Illness.

Sparkes, A. C. (1998). Athletic identity: An Achilles' heel to the survival of self. Qualitative Health Research, 8(5), 644-664.

Sparkes, A. C., \& Smith, B. (2003). Men, sport, spinal cord injury and narrative time. Qualitative Research, 3(3), 295-320.

Sparkes, A. C., \& Smith, B. (2005). When narratives matter. Medical Humanities, 31, 81-88. 
Swain, J., \& French. S. (2000) Towards an Affirmative Model of Disability, Disability \&

Corresponding author's e-mail address: Society, 15(4), 569-582.

B.M.Smith@exeter.ac.uk

\section{BEHINDERTER KÖRPER UND IN GESCHICHTEN GEKLEIDETES SELBST: EIN BEISPIEL FÜR QUALITATIVE UNTERSUCHUNG UND ERZÄHLENDE FORSCHUNG}

(Resümee)

Basierend auf lebensgeschichtlichen Daten untersucht dieser qualitativer Beitrag die Selbstbilder einer kleinen Gruppe von Männern, die aufgrund einer Rückenmarksverletzung, erlitten beim Rugby-Spielen, den Wechsel von der Welt der Nichtbehinderten in die Welt der Behinderung gemacht haben - in der sie bis heute verbleiben. Die gebräuchlichsten Arten der Selbstwahrnehmung, die diese Männer durch das Erzählen ihrer Lebensweise nach der Verletzung benutzen, werden detailliert fokussiert. Die narrativen Analysen ergeben, dass drei Typen von Erzählweisen dabei helfen, die Art und Weise wie diese Männer ihre verkörperte Selbstwahrnehmung erzählen, zu strukturieren und zu formen. Von der Mehrheit der Teilnehmer wurde eine „restitution narrative“ (erzählende Entschädigung) in Anspruch genommen, was dabei half ein wiederhergestelltes Selbstbewusstsein und ein fest verwurzeltes Selbst zu strukturieren, was wiederum an den disziplinierten Körper gebunden war. Im Gegensatz dazu berichteten zwei Personen über erzählende Sinnsuche, die eine sich entwickelnde und affirmative Selbstwahrnehmung konstituierte sowie einen Körper, der kommunikativ ist. Für eine Person stand ein erzählerisches Chaos im Vordergrund, was in einer fragmentierten Selbstwahrnehmung und einem chaotischen Körper in Aktion resultierte. Die sich aus all dem ergebenden Folgerungen für die Relation von Körper und Selbst von behinderten Personen werden kritisch in Betracht gezogen.

SCHLÜSSELWÖRTER: Behinderung , Erzählung, Selbst, Körper, Sport.

\section{PERSONNES EN SITUATION DE HANDICAP ET TEMOIGNAGES : EXEMPLE D'UNE ENQUETE QUALITATIVE ET D'UNE RECHERCHE A BASE DE TEMOIGNAGES}

(Résumé)

Basée sur des données issues de témoignages, cette étude qualitative étudie la perception qu'un petit groupe d'hommes blessés médullaires ont d'eux-mêmes. Ces derniers, blessés en jouant au rugby ou au football, sont passés du monde des valides au monde des personnes en situation de handicap. Les types de perceptions ressenties par ces hommes sont relatés à travers le témoignage de leur vie qui a suivi la blessure médullaire L'analyse des récits de vie révèle que trois types de témoignages structurent et façonnent la manière dont ces hommes se perçoivent. La majorité des participants ont eu recours à la restitution de ce qui leur est arrivé. Cela leur a permis de se reconstruire tout en gardant une image liée à ce qu'ils étaient avant l'accident, leur corps est discipliné. A l'opposé, deux personnes ont rapporté des récits de quêtes qui traduisent une perception d'eux-mêmes développée et affirmée ainsi qu'un corps communicatif. Pour l'un des participants, la déstructuration était au premier plan, cela résulte d'une fragmentation de la perception qu'il a de lui-même et d'un corps déstructuré en action. Les implications de tout cela sur la relation que les personnes en situation de handicap ont de leur propre corps sont ici sérieusement étudiées.

MOTS CLEFS: Handicap, Témoignage, Perception de Soi, Corps, Sport. 